\title{
Biological Variability and Measurement Error Varia- bility in Ocular Biometry in Samoyed Dogs
}

\author{
By B. Ekesten
}

Department of Medicine and Surgery, Faculty of Veterinary Medicine, Swedish University of Agricultural Sciences, Uppsala, Sweden.

\begin{abstract}
Ekesten, B.: Biological variability and measurement error variability in ocular biometry in samoyed dogs. Acta vet. scand. 1994, 35, 427-433. - A-scan ultrasonography was performed in 40 healthy Samoyeds aged 2-5 years. Mydriasis and cycloplegia were induced in all dogs and 25 of the dogs were also sedated prior to the ultrasound examination. Five consecutive A-scans were taken on each eye and the intrasubject variance (measurement error) and true intersubject variance (true biological variation) were computed. The true biological variation was found to be of the same magnitude in both sedated and unsedated dogs, whereas the measurement errors were considerably larger in the group of unsedated dogs compared to the sedated ones. Magnitudes of the measurement errors for the anterior chamber depth and length of the vitreous body in the unsedated group were unacceptable. The sizes of the measurement errors in the sedated dogs were all within an acceptable range.
\end{abstract}

\section{A-scan ultrasonography; ocular biometry; biological variation; dog.}

\section{Introduction}

Ocular biometry using A-scan ultrasonography has been performed in several studies in veterinary ophthalmology (Schiffer et al. 1982, Neumann 1988, Cottrill et al. 1989, Gaiddon et al. 1991, Ekesten 1992, Ekesten 1993). The purpose of performing ocular biometry in dogs has mainly been to either determine the axial length for calculation of the power of artificial intraocular lenses or to measure the sagittal size of intraocular structures in canine glaucoma. Further, ocular biometry is now in frequent use at certain veterinary clinics. Both A-scan and B-scan ultrasonography has been used for ocular biometry in euthanised dogs and it was found that the results were similar (Cottrill et al. 1989). However, it has been stated that A-scan is more accurate than B-scan for measuring intraocular distances (Coleman 1979). Seda- tion or anaesthesia of the canine patient is often used during ocular biometry, but it has been proposed that ocular biometry can be performed without anaesthesia or sedation (Gaiddon et al. 1991, Gelatt 1991).

The accuracy of a method for measuring biological parameters is dependent on the possibility of obtaining unbiased measurements with acceptable precision. Unbiasedness is defined as the tendency to arrive at the true value, whereas precision denotes the degree of spread in a series of measurements (Colton 1974). The bias of ocular biometry using Ascan has been studied in a number of investigations (Jansson 1963, Schiffer et al. 1982, Cottrill et al. 1989). Thus, correction for bias caused by different velocities of ultrasound in different parts of the eye can be performed, since the true distances have been determined with other methods, and constants of conver- 
sion are known (Jansson 1963, Schiffer et al. 1982). Imprecise measurements can certainly be more difficult to handle. Incorrect alignment of the probe along the optical axis of the eye and compression of the globe are for instance obvious sources of errors (Coleman 1979). Means of repeated measurements can sometimes be used to approach the true value, assuming that the number of repetitions is sufficient and that the distance is not altered by the procedure.

A measuring method is usually influenced by different sources of variation. Attention is often paid to 2 of the major sources of variation: true biological variability and measurement error variability. It is of great importance in all methods to establish that the measurement error is considerably smaller than the true biological variation within the sample. In the opposite case, the variation in results between different subjects is predominantly caused by an inaccurate method employed in the study. A useful and easily performed technique for determining and discriminating these variabilities is analysis of replicate measurements (Colton 1974). Ultrasonographic measurements repeated twice on eyes of anaesthetised cynomolgus monkeys have been shown to have high repeatability (Leary et al. 1969). However, estimates of measurement errors and biological variation in a clinical situation has, at least to the author's knowledge, not been determined for A-scan ultrasonography of the canine eye.

The aim of this study was to investigate the size and importance of the measurement errors in ocular biometry using A-scan ultrasonography in sedated and unsedated Samoyeds.

\section{Materials and methods}

A total of 40 pure-bred Samoyeds, aged 2 to 5 years, without evidence of intraocular or systemic disease were used in this study. The dogs were randomised into 2 groups, $\mathrm{A}$ and $\mathrm{B}$. Group A included 25 dogs (9 males and 16 females) with a mean age of $3.4 \pm 1.0$ years (mean age \pm one standard deviation), whereas group B contained 15 dogs (4 males and $11 \mathrm{fe-}$ males with the mean age $3.1 \pm 0.9$ years. After a general clinical examination, indirect ophthalmoscopy, slit-lamp biomicroscopy and tonometry (Oculab Tono-Pen ${ }^{\mathrm{TM}}$, Bio-Rad, Santa Ana, California) were performed on both eyes of all dogs in the order mentioned. One or 2 drops of a topical anaesthetic, tetracaine hydrochloride (Tetracain, Alcon Universal Ltd., Fort Worth, Texas), were instilled before performing tonometry. The dogs in group A were tranquillised using an intramuscular injection of $0.01 \mathrm{mg} / \mathrm{kg}$ of medetomidine hydrochloride (Domitor vet.: Lääkefarmos, Åbo, Finland), whereas the dogs in group B were unsedated. One drop of a topical cycloplegic, cyclopentolate (Cyclogyl 1\%, Alcon Universal Ltd., Fort Worth, Texas), was then instilled in both eyes of all dogs. Ultrasonographic biometry was performed $60-90 \mathrm{~min}$. after instillation of cyclopentolate. In order to obtain accurate topical anaesthesia and contact between the ultrasound probe and cornea, 1-2 drops of a tetracaine hydrochloride solution and 1-2 drops of a $1 \%$ methyl cellulose ophthalmic solution (Metylcellulosa 1\%: Apoteksbolaget, Stockholm, Sweden) were used immediately before biometry. The ultrasonographic examinations were performed between 10.00 a.m. and 1.00 p.m. in all dogs.

The ultrasonographic equipment used in this study included a $10 \mathrm{MHz}$ focused biometry probe with a built-in water bath (Storz Omega Compu-Scan: Storz Instrument Company, St. Louis, Missouri). A-scans were stored until 5 accepted scans of each eye were obtained (Schiffer et al. 1982, Ekesten 1993). The examination was always performed on the left eye first. The A-scans were then reviewed and 


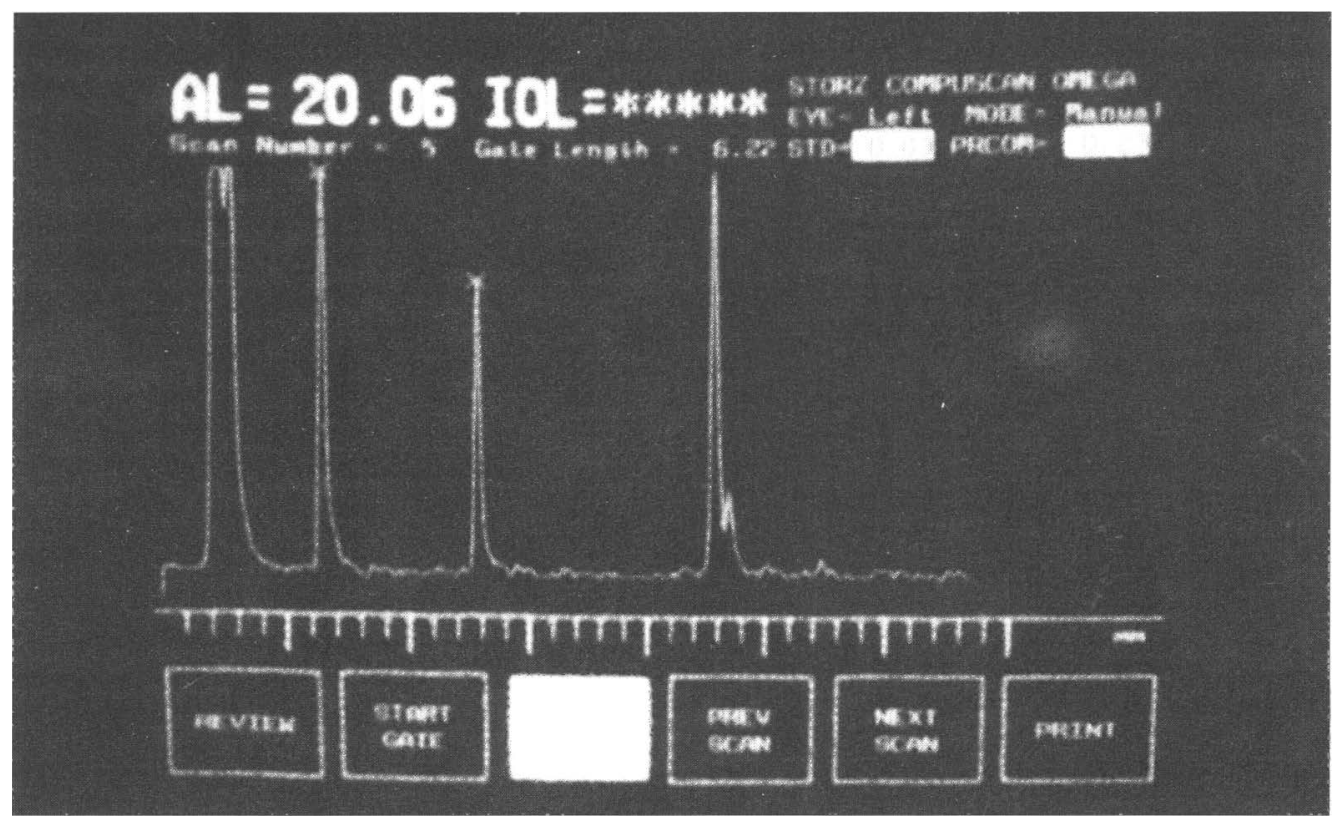

Figure 1. Display of the ultrasonographic equipment used in this study shows a characteristic A-scan tracing of the canine eye. The 4 easily discernible peaks are from left to right: anterior corneal surface, anterior lens surface, posterior lens surface and retina. The tracing is an automatically derived average of 512 A-scans and the standard deviation of these scans is shown on the display (STD) together with the compression of the soft probe tip (PRCOM).

measured by means of a built-in ruler function with $0.05 \mathrm{~mm}$ accuracy (Fig. 1 ). The biometric measurements shown in this paper are means of 5 accepted scans with correction for the tissue velocities that have been established for the canine eye (aqueous and vitreous 1526 $\mathrm{m} / \mathrm{s}$, lens $1710 \mathrm{~m} / \mathrm{s}$ ) (Schiffer et al. 1982). The distances measured were anterior chamber depth, lens thickness, length of the vitreous body and axial length. The depth of the anterior chamber was measured from the corneal epithelium to the anterior lens surface, thus including the thickness of the cornea.

The intrasubject variation (the variation within the subject) was calculated as the variance of the 5 consecutive measurements performed on each eye of the patient. Thus, the mean intrasubject variation was the sum of the intrasubject variance for all subjects divided by the number of subjects. The mean intrasubject variance is accordingly an estimate of the variation caused by measurement errors (Colton 1974). The true mean intersubject variation (the variation between the subjects) was calculated as the difference between the variance of the 5 consecutive measurements (the mean intersubject variation) and the mean intrasubject variance. The true mean intersubject variance is therefore an estimate of the true biological variation between the subjects.

In order to avoid statistical dependence the results from left and right eyes were analysed separately. Values obtained for the right and 
Table 1 . The mean intrasubject variances, true mean intersubject variances and ratios between the aforementioned measures for anterior chamber depth (AC), lens thickness (L), vitreous body (VB) and axial length (Ax) in group A (sedated Samoyeds) and group B (unsedated Samoyeds). Values obtained for the right and left eye are characterised by the subscript »r« and $»$ l respectively.

\begin{tabular}{|c|c|c|c|c|c|c|c|c|c|c|c|c|}
\hline \multirow[b]{2}{*}{ Group } & \multicolumn{4}{|c|}{ Intrasubject variance $\left(\mathrm{mm}^{2}\right)$} & \multicolumn{4}{|c|}{ Intersubject variance $\left(\mathrm{mm}^{2}\right)$} & \multicolumn{4}{|c|}{$\begin{array}{l}\text { Intersubject variance/ } \\
\text { Intrasubject variance }\end{array}$} \\
\hline & AC & $\mathrm{L}$ & VB & $\mathrm{Ax}$ & $\mathrm{AC}$ & $\mathrm{L}$ & VB & $A x$ & AC & L & VB & $A x$ \\
\hline $\mathrm{A}_{1}$ & 0.0083 & 0.0065 & 0.0054 & 0.0126 & 0.0557 & 0.0915 & 0.0571 & 0.2519 & 6.7 & 14.1 & 10.6 & 20.0 \\
\hline$A_{r}$ & 0.0073 & 0.0048 & 0.0047 & 0.0088 & 0.0508 & 0.0881 & 0.0592 & 0.3021 & 7.0 & 18.4 & 12.7 & 34.4 \\
\hline $\mathrm{B}_{1}$ & 0.0157 & 0.0118 & 0.0239 & 0.0177 & 0.0819 & 0.0990 & 0.0472 & 0.2771 & 5.2 & 8.4 & 2.0 & 15.7 \\
\hline$B_{r}$ & 0.0214 & 0.0171 & 0.0155 & 0.0216 & 0.0394 & 0.1266 & 0.0680 & 0.3574 & 1.8 & 7.4 & 4.4 & 16.6 \\
\hline
\end{tabular}

Table 2 The mean values for ocular distances measured by A-scan ultrasonography in this study; anterior chamber depth (AC), lens thickness (L), vitreous body (VB) and axial length (Ax). The results are subdivided into group A (sedated Samoyeds) and group B (unsedated Samoyeds). Values obtained for the right and left eye are characterised by the subscript $» r \ll$ and $» l \ll$ respectively. Mean values are given \pm one standard deviation.

\begin{tabular}{lcccc}
\hline Group & $\begin{array}{c}\text { AC } \\
(\mathrm{mm})\end{array}$ & $\begin{array}{c}\mathrm{L} \\
(\mathrm{mm})\end{array}$ & $\begin{array}{c}\text { VB } \\
(\mathrm{mm})\end{array}$ & $\begin{array}{c}\text { Ax } \\
(\mathrm{mm})\end{array}$ \\
\hline $\mathrm{A}_{1}$ & $4.50 \pm 0.25$ & $7.54 \pm 0.31$ & $10.04 \pm 0.25$ & $22.08 \pm 0.51$ \\
$\mathrm{~A}_{\mathrm{r}}$ & $4.49 \pm 0.24$ & $7.52 \pm 0.30$ & $10.05 \pm 0.25$ & $22.06 \pm 0.56$ \\
$\mathrm{~B}_{1}$ & $4.20 \pm 0.31$ & $7.62 \pm 0.33$ & $9.99 \pm 0.27$ & $21.81 \pm 0.54$ \\
$\mathrm{~B}_{\mathrm{r}}$ & $4.18 \pm 0.25$ & $7.63 \pm 0.38$ & $9.96 \pm 0.29$ & $21.77 \pm 0.62$ \\
\hline
\end{tabular}

left eye of the ocular distance measured is characterised by the subscript " $r$ " and "l" respectively. The comparisons of the intraocular distances between the groups were performed as a two-tailed Student's t-test for independent samples. Mean values of intraocular distances are given \pm one standard deviation (SD).

\section{Results}

A general impression was that the A-scan examinations were performed both faster and easier on the sedated dogs in group A than on unsedated dogs in group B. Although the majority of the dogs in the unsedated group could be held in lateral recumbency on the examination table without problems, rapid movements of the head and the globe made it difficult for the examiner to position the probe properly and avoid episodes of excessive compression of the tip of the probe and the eye. Furthermore, a sufficient number of accepted scans could not be obtained on the second (right) eye of a Samoyed bitch in group $\mathrm{B}$ due to the uncooperativeness of this patient. This eye has been excluded from the study.

The intrasubject variance and the true intersubject variance for group A and B are shown in Table 1. The mean ratios between true intersubject and intrasubject variance for both eyes for anterior chamber depth, lens thickness, length of vitreous body and axial length were $6.8,16.3,11.6$ and 27.2 respec- 
tively in group A. Corresponding values in group B were 3.5, 7.9, 3.2 and 16.1. The ratios of the corresponding distances were of the same size for both eyes in group A, whereas considerable differences were observed between the eyes in group B. Furthermore, it should be observed that the ratios were as low as approximately 2 for anterior chamber of the right eye and vitreous body of the left eye in group B. The intrasubject variances were 1.4 (axial length, left eyes) to 4.4 (vitreous body, left eye) times greater for group $B$ than the corresponding value in group $\mathrm{A}$, whereas the ratio of true intersubject variances between the groups were less than 1.5 for the distances measured.

The mean values of the ocular distances measured in this study are presented in Table 2. When the intraocular distances for each eye were compared between the groups, it was found that the anterior chamber depth was significantly different $\left(\mathrm{p}_{1}=0.002\right.$ and $\left.\mathrm{p}_{\mathrm{r}}<0.001\right)$. The anterior chamber was more shallow for both eyes in unsedated Samoyeds (group B) compared to the results from group A. Statistically significant differences could not be demonstrated either in lens thickness $\left(\mathrm{p}_{1}=0.45\right.$ and $\mathrm{p}_{\mathrm{r}}=0.36$ ), length of the vitreous body $\left(\mathrm{p}_{\mathrm{l}}=0.56\right.$ and $\left.\mathrm{p}_{\mathrm{r}}=0.35\right)$ or in axial length $\left(\mathrm{p}_{1}=0.17\right.$ and $\left.\mathrm{p}_{\mathrm{r}}=0.11\right)$.

\section{Discussion}

Clinical determinations of the size of anatomical structures are prone to several sources of variation. True biological variation, measurement error and temporal variation are probably the most important ones (Colton 1974). Factors causing temporal variation are difficult to control in dogs, but in order to diminish errors caused by circadian rhythms, most of the examinations were performed in the middle of the morning. In order to avoid differences in intraocular distances caused by the initial, rapid growth of the eye, the age range of the dogs was chosen as $2-5$ years. Age is certainly an important source of biological variation and what is called true biological variation in this study is probably caused to a fairly small extent by age-related changes in intraocular distances.

Ideally, biometry should have been performed on the same dogs without and with sedation, but since all Samoyeds were out-patients, practical considerations made this impossible. However, the true biological variation (true intersubject variation) was of the same magnitude in both groups. Random allocation of the dogs to the groups and equal biological variation suggest that the Samoyeds in both groups could be considered to represent similar populations and the problem of using different dogs in group A and B could thus be neglected in this study. Furthermore, light sedation with medetomidine hydrochloride does not obviously alter the true biological variation.

The measurement errors (intrasubject variation) and the differences in intrasubject variation between the eyes were considerably smaller in group A compared to group B. These differences between the groups show clearly that light sedation considerably increases precision in ocular biometry. The ratios between true biological variation and measurement errors are acceptable in group A. Ratios close to 2 for two distances in group $\mathrm{B}$ show that the precision in this group is nothing else but insufficient. The parameter with the smallest mean ratio in group A is the axial anterior chamber depth and this parameter has a very small mean ratio in group B too. Further, the anterior chamber depth was also significantly smaller in group B than in group A. This is explained by the fact that the depth of the anterior chamber is the ocular distance most sensitive to the force applied to the eye 
during examination. This is supported by the subjective impression of the examiner that a considerably greater force was applied to the eyes by the probe and by the fingers in keeping open the eyelids of the dogs in group B compared to Samoyeds in group A. The shorter axial length of dogs in group B compared to Samoyeds in group A, although not statistically significant, is most likely an effect of a compressed, more shallow anterior chamber. The small ratio between true biological variation and measurement error for the vitreous body in group $\mathrm{B}$ cannot mainly be caused by compression, since there is no significant difference in its length compared to the value in group A. Thus, the cause of error is likely to be a tendency for incorrect alignment of the probe along the optic axis due to eye and head movements, causing a large error of measurement. A similar difference was observed in the precision of measurements of lens thickness between the groups.

Sedation of the patients was also favoured by the examiner and without any doubt also by at least some of the patients and their owners. The subjective opinion of the examiner is that the biometric measurements were obtained with considerable greater ease on sedated Samoyeds compared to unsedated dogs and the time required for the examination was generally shorter. Stress and discomfort were also reduced, both for anxious Samoyeds and worried owners. Furthermore, it must be stressed that only light sedation is advantageous. The experience of the examiner is that ocular biometry of heavily sedated dogs is accompanied by several disadvantages. The globe is usually rotated downwards-nasally and the nictating membrane is protruded in heavily sedated dogs. This implies that the globe has to be manipulated to make it possible to position the probe correctly, which interferes with the examination.
The conclusion is that A-scan ultrasonography is an accurate method in determining intraocular distances in the canine eye in vivo if certain measures are taken to obtain unbiased, precise values. The velocity of ultrasound is altered by the tissues in the eye and the measurements obtained then have to be corrected for the differences in tissue velocities to achieve unbiased values (Jansson 1963, Schiffer et al. 1982). Furthermore, this study has shown that the precision is acceptable if biometry is performed on lightly sedated Samoyeds in which cycloplegia and mydriasis have been induced. It should be noticed that the anterior chamber depth, a distance of major importance in glaucoma dogs, is obviously altered when measurements are performed on unsedated dogs. Also other ocular distances, for instance the axial length which is used for the calculation of power of intraocular lens implants, may be changed in unsedated dogs. Sedation of the patient also enhances the examination procedure in A-scan ultrasonography and relieves the stress and discomfort of some of the patients.

\section{Acknowledgements}

The study was supported in parts by the Research Foundation of the Agria Insurance Company and Thure F and Karin Forsberg's Foundation, Stockholm, Sweden and the Albert Hjärre Foundation, Uppsala, Sweden. The author thanks Swedish breeders and owners of Samoyed dogs for assistance and Professor Kristina Narfström for valuable advice.

\section{References}

Coleman DJ: Ultrasonic measurements of eye dimensions. Int. Ophthalmol. Clin. 1979, 19, 225 236.

Colton T: Statistics in medicine. First ed. Boston: Little, Brown and Company 1974, 372 p.

Cottrill NB, Banks WJ, Pechman RD: Ultrasonographic and biometric evaluation of the eye and orbit of dogs. Amer. J. vet. Res. 1989, 50, 898903. 
Ekesten B: Mätning av intraokulära avstånd på hund med och utan inverkan av ett cykloplegicum. (Measurement of intraocular distances with and without the use of a cycloplegic agent.) Svensk Vet. tidning. 1992, 44, 199-202.

Ekesten B: Correlation of intraocular distances to the iridocorneal angle in Samoyeds with special reference to angle-closure glaucoma. Prog. Vet. Comp. Ophthal. 1993, 3, 67-73.

Gaiddon J, Rosolen SG, Steru L, Cook CS, Peiffer Jr $R$ : Use of biometry and keratometry for determining optimal power for intraocular lens implants in dogs. Amer. J. vet. Res. 1991, 52, 781783.

Gelatt KN: Ophthalmic examination and diagnostic procedures. In: Gelatt $\mathrm{KN}$ (ed.). Veterinary Ophthalmology. Second ed. Philadelphia: Lea \& Febiger 1991, pp. 195-235.

Jansson F: Measurements of intraocular distances by ultrasound. Acta Ophthalmol. (Copenh.) 1963, (Suppl. 74), 1-50.

Leary GA, Young FA: Reliability and validity of ultrasonographic measurements in primates. In: Gitter K, Keeney A, Sarin L, et al. (eds.): Ophthalmic ultrasound. Saint Louis: The CV Mosby Company 1969, pp. 117-121.

Neumann W: Biometrie am Hundeauge. (Biometry of the canine eye.) Kleintierpraxis 1988, 33, 127130.
Schiffer SP, Rantanen NW, Leary GA, Bryan GM: Biometric study of the canine eye, using A-mode ultrasonography. Amer. J. vet. Res. 1982, 45, 826830.

\section{Sammanfattning \\ Biologisk variation och mätfel vid okulär ultraljuds- biometri av samojedhundar.}

Ultraljudsundersökning av ögat med hjälp av A-scan utrustning genomfördes på 40 friska samojedhundar i åldern 2-5 år. Mydriasis och cykloplegi inducerades hos samtliga hundar och 25 av dessa hundar sederades även med medetomidin före undersökningen. Fem på varandra följande ultraljudsmätningar genomfördes på varje öga och variationen inom varje öga (mätfelet) och variationen mellan ögonen i respektive grupp (biologisk variation) beräknades. Den biologiska variationen var av samma storleksordning hos både sederade och osederade hundar, medan mätfelen var påtagligt högre i gruppen med osederade samojeder jämfört med de sederade. Mätfelen för främre ögonkammarens djup och glaskroppens längd i den osederade gruppen var av icke acceptabel storleksordning, medan mätfelen för samtliga avstånd var inom godtagbara gränser för hundarna i den sederade gruppen.

(Received March 1, 1994; accepted September 8, 1994).

Reprints may be requested from: B. Ekesten, Department of Medicine and Surgery, Faculty of Veterinary Medicine, Swedish University of Agricultural Sciences, P.O. Box 7037, S-75007 Uppsala, Sweden. 